\title{
A MODEL OF DISCRETE ZERO-SUM TWO-PERSON MATRIX GAMES WITH GREY NUMBERS TO SOLVE DISPUTE RESOLUTION PROBLEMS IN CONSTRUCTION
}

\author{
Mostafa KHANZADI ${ }^{\mathrm{a}}$, Zenonas TURSKIS ${ }^{\mathrm{b}}$, Gholamreza GHODRATI AMIRI ${ }^{\mathrm{c}}$, \\ Alireza CHALEKAEE ${ }^{\mathrm{d}, \mathrm{e}}$ \\ ${ }^{a}$ School of Civil Engineering, Iran University of Science \& Technology, Narmak, 16846, Tehran, Iran \\ ${ }^{b}$ Department of Construction technology and Management, Faculty of Civil Engineering, \\ Vilnius Gediminas Technical University, Sauletekio al. 11, LT-10223, Vilnius, Lithuania \\ ${ }^{c}$ Center of Excellence for Fundamental Studies in Structural Engineering, School of Civil Engineering, \\ Iran University of Science \&Technology, Narmak, 16846, Tehran, Iran \\ ${ }^{d}$ School of Civil Engineering, Iran University of Science \& Technology, Narmak, 16846, Tehran, Iran \\ ${ }^{e}$ Research Laboratory for Advanced Construction Technologies and Management, \\ Vilnius Gediminas Technical University, Sauletekio al. 11, LT-10223, Vilnius, Lithuania
}

Received 12 Jan 2017; accepted 12 Apr 2017

\begin{abstract}
Conflict between parties is a common issue in construction projects. In the present article, the conflicts between contractor and employer in delayed Design-Bid-Build projects have been studied. Defining a case study, a dispute resolution method has been proposed. This case has been considered as a MCDM problem. This problem has been assumed as a discrete zero-sum two-person matrix game with grey numbers. Among the four alternatives available for contractor and employer in the proposed case study, termination is the last alternative that decision makers choose. Based on different risk values, authors determined the optimal solution for both parties. This article integrates some linguistic criteria together with time and cost, providing the better conditions to avoid lengthy bargaining.
\end{abstract}

Keywords: MCDM, construction delay, dispute resolution, game theory, ADR, grey number.

\section{Introduction}

Successful implementation of the projects is a vital issue for stakeholders as well for construction companies. Conflict is a common issue between different participants in a project, regardless of project's delivery system. As different parties follow their own interests, even conflict between them might be beneficial in fulfilling project's main aims. Different researchers agree in the core idea that interest conflict is not a concern for the project, until it ignites the dispute between parties of a project (Gardiner 2005; Sunindijo, Hadikusumo 2014) such research has not been done in the construction industry particularly by considering the influence of sociocultural norms. Data were collected using questionnaire surveys from project managers and engineers (PMEs). Dispute can affect project's scope, make it more costly, prolong it or reduce its final quality. Also, more disputes in a project may cause some subtle effects, as rising tensions between the parties. Usually when finding a resolution for a dispute is prolonged, decision-makers have to choose more expensive Dispute Resolution Method (DRM) (Kassab et al. 2010; Chen et al. 2014). Different DRMs have been proposed.
Alternative Dispute Resolutions (ADRs) are the methods that parties try to settle the disputes with them unofficially and without litigation. Negotiation, Mediation, Partnering, Adjudication, Dispute Review Boards, Arbitration, and Conciliation are the most accepted ADRs in different researches (Kassab et al. 2006; Chong, Zin 2012; Song et al. 2014; Lee et al. 2016). Choosing the most appropriate ADR for a project is complicated. A project is composed of numerous elements having trade-offs between economical, qualitative and socio-political issues (Peldschus et al. 2010). That makes calculation of project stakeholders' payoffs complex or sometimes incomputable. From this point of view, different researchers used different multi-criteria decision-making methods for ADRs in different cases (Šostak, Vakrinienè 2011; Šostak, Makutenienè 2013a, 2013b; Yousefi et al. 2016). Dispute resolution problems require multi-criteria decision-making methods, decision-makers' judgments and evaluations about alternatives performance regard to multiple criteria. Also, in all of the dispute problems decisions should be made for a change in future, and the decisions re-

Corresponding author: Mostafa Khanzadi

E-mail:khanzadi@iust.ac.ir 
lating to future always have some uncertainty in their nature. Theory of Grey numbers proposed by Deng $(1982,1989)$ to deal with uncertainty and incomplete information.In general, dispute resolution is concerned with situations where the payoffs of two or more parties depend on their actions, and the final outcomes are not defined by no-single party.

Game theory is a resolution method (Peldschus, Zavadskas 2011) when rational and strategic decision-makers have conflicts among their interests. It provides a mathematical process for selecting an optimal strategy (Turskis et al. 2009; Medineckiene et al. 2011). Fang et al. (2010) suggest that grey extension of game theory methods is feasible. So, in this situation, a disputed problem between parties could be defined as discrete zero-sum matrix game with grey criteria values.

Based on the timing of decision making, games are being divided into two types: static and dynamic. In a static game, players act without any information about other players' decision; while in dynamic games, any action of a player result in the reaction originating from other players in the next round. In other words, in static games players act simultaneously. For this reason, static games are usually being depicted in matrix form, while tree-like diagrams (extensive form) are the normal depiction of dynamic games.

Delay is a common source of dispute in different projects. Any parties of a project might be responsible for the delay cause (Chan, Kumaraswamy 2002; Assaf, Al-Hejji 2006; González et al. 2014; Kadry et al. 2016). So, when a problem relating to delay is being settled, these different parties must decide about their share in delay occurrence. When focusing on DBB projects, both of contractor and employer have a trade-off in delayed cases. In a delayed project, the employer will have less profit because of late operation, also for some socio-political reasons he will bear a social pressure. In addition, a contractor must pay the delay penalty, so he may provide his claim relating to inflation and increased overhead costs resulting from the prolongation of the project. During the delay resolution process, debilitation of their relation will be probable. This will affect the reputation of the both employer and contractor in any bids in future. Therefore, both parties intend to reduce the delay. So, during finding the proper ADR relating to delay, the conflict between their payoffs will occur (Khanzadi et al. 2016). Fang et al. (2010) introduced the concept of information loss into the classic game theory as grey game theory. Grey game theory might be applied to the disputed situations with uncertainty about future and limited or poor knowledge. So, it is feasible to extend game theory methods with grey values. This paper is organized as follows. A literature review of dispute resolution and the problem of delay in construction projects is first presented as the introduction to define the scope of this research. Based on the literature review, the proposed framework as a ADR is explained. Then, the employer-contractor relationship of the DBB projects in Iran is presented, and the proposed case study of a project facing the problem of delay is defined. This real case dispute resolution study is considered as a discrete zero-sum two-person matrix game with grey numbers. Defining the initial game matrix, criteria and alternatives of the players are proposed. Then, weight factors of the criteria are determined by AHP method and the solutions are calculated with grey number rules. Finally, conclusions are presented based on the obtained results.

\section{Previous studies}

We divide the literature review into two parts: Dispute resolution methods and Grey number theory.

\subsection{Dispute resolution methods}

Numerous researches have been done to realise the nature of disputes in a construction project. They can be categorized in three main branches: finding the causes of the disputes (Jaffar et al. 2011), proposing the procedures to decrease or avoid the disputes (Harmon 2003; Song et al. 2104) and dispute resolution methods (Cheung et al. 2010; Yousefi et al. 2010; Chou 2012). Researchers used different tools for dispute resolution presentation. In Kassab et al. (2006), a graph model based conflict resolution DSS was presented as GMCR II that investigate the owner-contractor interactions. They used this DSS in different articles (Kassab et al. 2010, 2011; Hipel et al. 2011). Gebken and Gibson (2006) proposed a dispute resolution framework based upon the concepts of risk management. Chan et al. (2006) presented a dispute resolution selection model based on AHP and MAUT. Also, Cheung and Suen (2002) proposed their dispute resolution strategy selection model using multi-attribute utility. $\mathrm{Ng}$ et al. (2007) proposed a conflict management system for large-scale design and construction projects using dynamics of system. El-adaway and Kandil (2010) have simulated disputes and proposed a dispute resolution system in construction projects using logical algorithms. Some researchers studied the most appropriate dispute resolution for their countries (Chong, Zin 2012; Chan, Suen 2005). Reviewing the above-mentioned papers, uncertainty has been applied to them as an element while deciding about the future.

Also, game theory has been applied to the problems of disputes between participants in construction projects during the recent years. Ho and Liu (2004) proposed a unique game theoretic model for opportunistic bidding. Also, Ahmed et al. (2016) studied the winner's curse; a situation may happen for a contractor with winner bid. Kassab et al. (2010) used game theory to study the conflicts between participants of the construction projects, under uncertainty. Other researchers (Ho 2006; Tserng et al. 2012, 2014; Javed et al. 2014; De Clerck, Demeulemeester 2016; Li et al. 2017) used game theory to facilitate the condition of public-private partnership. Shen et al. (2007), Chen et al. (2012), Lv et al. (2015) proposed recommendations to ease the bargaining process in BOT projects. Ho (2005) proposed a model for contractors, when the bid preparation is costly. In another research, the contracts with heterogeneous bidders were studied, 
using game theory. Ho and Hsu (2014), Unsal and Taylor (2011), Asgari et al. (2014) proposed resolutions for sub-contractors' conflicts. Hsueh and Yan (2011) used game theory for a profit-sharing scheme in joint ventures. Naderpajouh et al. (2014) used it in risk management between developer and opposition in infrastructure developments. Also, game theory has been used in the payment problems (Wu et al. 2011), renewal of construction objects (Antuchevičiene et al. 2006), cooperation during project delivery (He et al. 2016), and post-disaster management (Eid et al. 2015). Even some researchers have used game theory in studying the delayed projects (Castro et al.2007; Estévez-Fernández 2012). Khanzadi et al. (2016) proposed a mathematical model for analysis of the interactions between the contractor and employer of a DBB project.

\subsection{Grey number theory}

Grey theory is a technique for performing prediction, relational analysis and decision-making in many areas. Consider an MCDM problem that consists of evaluation of a set of $m$ alternatives (strategies) regard to a set of $\mathrm{n}$ attributes. These judgments are a subject of uncertainty. This methodology originally is proposed under crisp data in the LEVI-4 software. However, uncertainty and fuzziness in many situations are indubitable properties of decision-making problems in construction due to uncertainty or lack of information. Thus, it makes the use of crisp numbers problematic in decision-making. Decision-makers do not have complete information about alternatives or their conditions regard to a certain attribute. Decision-makers are usually more comfortable providing intervals for specific model input parameters. Grey systems theory is a powerful tool when solving similar problems. Deng (1982) developed the Grey system theory and presented grey decision-making systems (Deng 1989). A grey number (Lin et al. 2004) is a number whose exact value is unknown, but a range within which the value lies is known.

There are several types of grey numbers:

- Grey numbers with only lower limits $\otimes x \in[\alpha, \infty)$ or with only upper limits $\otimes x \in(-\infty, \beta]$ called the black numbers which means without any meaningful information.

- Interval grey number is the number with both lower limit $\alpha$ of $\otimes x$ and upper limit $\beta$ of $\otimes x$ :

$$
\otimes x=[\alpha, \beta]=\{x \mid \alpha \leq x \leq \beta, \alpha \text { and } \beta \in \mathbb{R}\} .
$$

Else if $\alpha=\beta$, then $\otimes x$ is called the white number which means with complete information.

- Continuous grey numbers and discrete grey numbers. The grey numbers taking a finite number of values or a countable number of values in an interval are called discrete. The continuously taking values, which cover an interval, are continuous.

Nevertheless, the obtained information from the real world is always uncertain or incomplete. Hence, extending the applications from white numbers (crisp values) to grey numbers is necessary for real-world applications. The basic definitions and operations of grey number described as follows.

Let,,$+- \times$ and $\div$ denote the operations of addition, subtraction, multiplication and division, respectively. According to the interval of confidence (Kaufman, Gupta 1985), some main operations of positive grey numbers $\otimes n_{1}$ and $\otimes n_{2}$ can be expressed as follows (Turskis, Zavadskas 2010):

$$
\begin{aligned}
& \otimes n_{1}+\otimes n_{2}=\left(n_{1 \alpha}+n_{2 \alpha}, n_{1 \gamma}+n_{2 \gamma}\right), \text { Addition; } \\
& \otimes n_{1}-\otimes n_{2}=\left(n_{1 \alpha}-n_{2 \gamma}, n_{1 \gamma}-n_{2 \alpha}\right), \text { Substraction; (3) } \\
& \otimes n_{1} \times \otimes n_{2}=\left(n_{1 \alpha} \times n_{2 \alpha}, n_{1 \gamma} \times n_{2 \gamma}\right), \text { Multiplication; (4) } \\
& \otimes n_{1} \div \otimes n_{2}=\left(\frac{n_{1 \alpha}}{n_{2 \gamma}}, \frac{n_{1 \gamma}}{n_{2 \alpha}}\right), \text { only if } n_{1 \alpha}, n_{2 \alpha}, n_{1 \beta}, \\
& \text { and } n_{2 \beta} \text { does not contain } 0, \\
& \text { Division; }
\end{aligned}
$$

$$
k \times\left(\otimes n_{1}\right)=\left(k n_{1 \alpha}, k n_{1 \gamma} \beta\right), \text { Number product }
$$

of grey numbers if $k$ is possitive real number.

\section{Research methodology}

The core idea in this study is presenting a dispute resolution for construction projects with a problem, delay. As an ADR, a game theoretic comparison method is proposed to prioritise the different alternatives available for contractor and employer of a project, when they face a dispute in a delayed project. A new extension of twoperson zero-sum discrete matrix Game theory is proposed where the decision-maker's judgments are expressed as grey numbers to consider the vagueness of dispute, two sides' opinion and importance weight of attributes in this paper. Like original LEVI-4 software's methods, the grey attributes weight vector is determined and alternatives are ranked according to their weighted values. Application of the proposed method is illustrated in a real numerical example in which is solved dispute problem. The expert team was formed to describe criteria set, determine criteria values, and weights.

The situation is considered as an MCDM problem and the proposed framework (Fig. 1) is used with the following steps:

- Defining the possible alternatives available for the decision-makers;

- Choosing the criteria affecting the MCDM problem, based on literature review;

- Criteria's weight factor determination using the AHP pair-wise comparison based on experts' judgement;

- Criteria value calculation in cooperation with both parties' ideas;

- Priority ranking of the alternatives through resolving a zero-sum two-person matrix game with grey numbers. 


\begin{tabular}{|l|l|l|l|l|l|l|}
\hline $\begin{array}{l}\text { Define the } \\
\text { alternatives }\end{array}$ & $\begin{array}{l}2 . \\
\text { collect the criteria } \\
\text { affecting the } \\
\text { problem }\end{array}$ & $\begin{array}{l}3 . \\
\text { Set up an expert } \\
\text { team }\end{array}$ & $\begin{array}{l}4 . \\
\text { Determine the } \\
\text { weight factors of } \\
\text { the criteria }\end{array}$ & $\begin{array}{l}5 . \\
\text { Determine the values } \\
\text { of alternatives for all } \\
\text { the criteria }\end{array}$ & $\begin{array}{l}6 . \\
\text { Rank the alterna- } \\
\text { tives }\end{array}$ & $\begin{array}{l}7 . \\
\text { Make the } \\
\text { decision }\end{array}$ \\
\hline
\end{tabular}

Fig. 1. The proposed dispute resolution framework for delayed construction projects

\section{Case study}

A brief description of the DBB projects is presented in the following section; then the proposed case study is described.

\subsection{DBB projects}

Design-Bid-Build (DBB), also known as the traditional method is a project delivery system in which the employer (owner) of a project contracts with the general contractor(s) for the construction phase, and consultant(s) for the design phase, separately. This delivery system is usually more disputed than other delivery systems like Design-Build; because different parties engage during the design and construction phase which leads to lack of coordination.

Iran is the largest industry market in the Middle East. A large number of implemented construction projects fall over a wide range, from housing section to oil field development. State (public sector), the major employer in Iran's construction industry, uses different project delivery systems. Design-Bid-Build is the most widely used system.

Iran has its own uniform DBB projects' contract agreement, "Sharayet Omoomi Peyman" (Management and Programing Organization of Iran 1999), which has not been revised lately. Irrationality is a major problem of this agreement. In the numerous clauses of it, risks have not been allocated logically among the project participants and most of them to contractor. This unrealistic risk allocation may lead to some undesirable changes in the project. As a concrete result, when a contractor has to manage these risks, he may affect quality or duration of a project. Consequently, the probability for unfavourable situations such as opportunistic bidding, higher transaction costs, wastage of parties' relations and jeopardizing parties' public reputation will rise. All of these situations can intensify the disputes between the participants in a project and lead to hostile situations. For this unfair risk allocation, the range of dispute among the DBB projects in Iran is high. So, rational suggestions should be devised to decrease or resolve these disputes. During the recent years, a trend for rectification of this vulnerable condition has arisen. Hence, the tendency to other delivery systems has been increased, and government tries to keep the friendly atmosphere in dealing with the contractors and treat more rationally with them. But still, DBB is the most common project delivery system for public projects in Iran. So, authors believe that proposing the appropriate ADR for DBB projects in Iran is in priority.
In the present article, we intend to investigate a widespread problem, delay. In a DBB project facing delay, with any delay cause, employer and contractor must find the best resolution for the dispute. In the previous article (Khanzadi et al. 2016) the different options both of the parties have as the solutions to this problem was presented. In a delayed project and according to the solutions that "Sharayet Omoomi Peyman" is presented, parties have six different options. They are as follows: 1- Continuation of the delayed project with the current trend; 2 - Contractor's own decision for delay reduction, without any request from the employer; 3 Compensation of the total delay, when the employer asks for it; 4 - Agreement between two parties about compensation of a part of the delay; 5 - Contract termination; and 6 Contract cancellation.

It should be noted that according to "Sharayet Omoomi Peyman" when the owner decides to cancel the project, contractor's bank guarantee related to the contract will be confiscated in the interest of the owner. In fact the major difference between termination and cancellation is the confiscation of contractor's guarantee in the cancellation (Khanzadi et al. 2016; Management and Programing Organization of Iran 1999). In this article, we will propose the best solution that is the best for both parties among the above-mentioned options with a case study. Hence, at first, we would find the effective criteria affecting the best solution for the delay dispute. The weight factors are determined by AHP pair-wise comparison. In the next step and by calculating the value of criteria for all of the available options, the optimal solution for both parties is defined with different game theory rules.

It is worth mentioning that the agreement of a contract is the core subject while studying the disputes in projects. So, any dispute resolution proposition for any project in any situation should be in compliance with the governing agreement of the project. The possible alternatives for the decision-makers are mentioned in the contract, and they should choose the most appropriate decision among them. Although the proposed framework (Fig. 1) is suitable for DBB project in Iran, it is possible to be applied to the projects which two decision-making parties face a dispute problem. Updating this framework for those projects, available alternatives for decisionmakers should be defined based on the contract. Also, the criteria effective in decision-making should be reevaluate for the conditions of those projects.

\subsection{Problem description}

In 2008, Ministry of Roads \& Urban Development of Iran intended to construct a highway in Tehran province. After a positive feasibility study, a consulting engineers group 
was asked to conduct the designs. Based on the consulting engineers' estimates, it was a 95 kilometres highway project, with a value of around $\$ 150$ million, consisting of different tasks, such as earthwork, pavement and civil activities. Employer (Ministry) decided to choose the contractor based on the competitive bidding. So, different contractors submitted their bids and the contract was awarded to the contractor with the lowest bid of $\$ 146$ million.

The initial duration of the project was 60 months. Tracking the cost and time deviations, project control had been done by the consulting engineers since the start of the project. Based on a project control report at the 53rd month of the project, employer concluded that the project would have an 8-months delay. It was the third report in a row that showed the probable delay. Then, employer intended to ask the contractor to find a resolution for the delay problem. Regardless of the causes of the delay occurrence, they found four possible options (alternatives) they might have for a delay resolution. First option: when the meeting started, contractor declared that his company is the cause of a part of the delay. So, the contractor would compensate 3.2 months of the delay. But, causes of the remaining 4.8 months are the factors out of contractor's authority. Second option: on the other hand, the employer believed that contractor should compensate the total delay. Third option: as the required conditions in the contract for the contract termination was satisfied, employer could terminate the project. It should be mentioned that contractor could not ask for a termination, as he was not entitled the permission by the contract. Fourth option: both parties continue their negotiations about a resolution for the problem. As a result, contractor declared that he might compensate 4.4 months of the delay if an employer would ignore the delay fine. Contractor and employer concluded that these four options are the available alternatives for the resolution of the problem. So, we represent them as: $\boldsymbol{A}_{\mathbf{1}}$ (first option): Delay reduction by the contractor; $\boldsymbol{A}_{2}$ (second option): Compensation of the total delay by the contractor; $A_{3}$ (third option): Compensation of a part of delay; $\boldsymbol{A}_{4}$ (fourth option): Contract termination.

Besides, each of the above-mentioned options may have adjunct payoffs that are hard to calculate, such as prestigious costs for both parties when they choose an option and etc. (Khanzadi et al. 2016). In the next section, we propose different criteria relating to the problem. As it was discussed in the introduction, the payoffs relating to the above-mentioned alternatives are different. In the next sections, we will discuss these payoffs more detailed.

\subsection{Defining the criteria set}

In order to have an accurate resolution for the delay problem, it is necessary to define all possible criteria affecting the decision making. The criteria were defined after a two-stage selection procedure. At the first step, authors listed the most important dispute resolution criteria that have been men- tioned in the literature (Keršuliene et al. 2010; Khanzadi et al. 2016). Then, this list was presented to an expert team. This expert team consisted of six people with construction experience as contractor or owner. This team choose eight most important criteria in the present dispute resolution problem. They believed that these criteria can probably reflect the total payoff for parties involved in the dispute. In Table 1 these criteria are shown. Cost $\left(x_{1}\right)$ shows the amount of direct cost incurred to each party for the alternatives $\left(A_{1}-A_{4}\right)$. We discuss this criterion in the next sections. Delay duration $\left(x_{2}\right)$ shows how long each of the alternatives makes the project longer. The total payoff for each party consists of some direct and indirect values. Criteria $x_{3}-x_{8}$ are linguistic criteria to calculate the indirect payoff. Each party calculates his own criteria value for the alternatives because he is the most knowledgeable individual familiar with his own situation. The uncertainty of the information $\left(x_{3}\right)$ was defined because the values have some degrees of uncertainty. Each alternative has some effect on the relations between both parties. The criterion $x_{4}$ shows how much an alternative affects the amicable relations between parties in the future. Prestigious costs $\left(x_{5}\right)$ have a different meaning for each party. For the contractor, it shows how much choosing each alternative may damage his prestige in the eyes of the employers in future. Also for employer, it shows how much choosing each alternative may jeopardize owner's reputation for inability in a promotion of the objectives and completion of the project on time and also weaken his position against other contractors. The criterion $x_{6}$ shows how much each party would be satisfied if an alternative is chosen. The criterion $x_{7}$ shows how much each party's authority is free to solve the problem during the negotiation with the opposite side. The criterion $x_{8}$ shows the possibility to appeal if a party would not be satisfied with the selected dispute resolution. Authors believe that these eight criteria can estimate the real payoff relating to each alternative with an acceptable accuracy.

\subsection{Determining the criteria weights}

There are different criteria weight estimation methods, for example decision maker's preferences, Delphi, Fuzzy weighted average, DEMATEL, ANP, AHP, etc. In this research, Analytic Hierarchy Process (AHP) (Saaty 1980) has been used for this purpose. It is a widely used method for criteria weighting not only used in construction projects (Lee 2015; Nguyen et al. 2015; Plebankiewicz, Kubek 2015; Polat 2015; Wang et al. 2016), but also in other branches. It is an easily implemented method that can detect and even unite the inconsistent data assessed by different experts (Wang et al. 2016). In this research, experts are asked to do a pair-wise comparison between the criteria available in Table 1. Their comparison was based on the judgement scale available in Table 2.

It should be noted that as the criteria in this research have different values for both parties, it is preferred to determine two weight factors for every criterion, each for one of the parties. An expert team consisted of $7 \mathrm{mem}$ bers with at least 10 years of experience in DBB projects 
Table 1. Criteria of the dispute resolution of the delay problem

\begin{tabular}{|c|c|c|}
\hline Criteria & $\begin{array}{c}\text { Unit of } \\
\text { measurement }\end{array}$ & Optimal \\
\hline $\operatorname{Cost}\left(x_{1}\right)$ & Million \$ & Min. \\
\hline Delay duration $\left(x_{2}\right)$ & Month & Min. \\
\hline Uncertainty of the information $\left(x_{3}\right)$ & Scores (1 to 5) & Min. \\
\hline $\begin{array}{l}\text { Preservation of the amicable } \\
\text { relations between parties }\left(x_{4}\right)\end{array}$ & Scores (1 to 5$)$ & Max. \\
\hline Prestigious costs $\left(x_{5}\right)$ & Scores $(1$ to 5$)$ & Min. \\
\hline $\begin{array}{l}\text { Satisfaction of parties with } \\
\text { outcome of the dispute }\left(x_{6}\right)\end{array}$ & Scores (1 to 5$)$ & Max. \\
\hline $\begin{array}{l}\text { Authority freedom of the person } \\
\text { solving the dispute }\left(x_{7}\right)\end{array}$ & Scores (1 to 5$)$ & Max. \\
\hline $\begin{array}{l}\text { Possibility to appeal against the } \\
\text { decision concerning the dispute } \\
\left(x_{8}\right)\end{array}$ & Scores (1 to 5$)$ & Max. \\
\hline
\end{tabular}

Table 2. AHP judgement scale

\begin{tabular}{l|c}
\hline Judgement & Score \\
\hline Equal & 1 \\
Barely superior & 2 \\
Moderately superior & 3 \\
Definitely superior & 4 \\
Strongly superior & 5 \\
Very strongly superior & 6 \\
Absolutely superior & 7 \\
\hline
\end{tabular}

of Iran were set up to find the weights. In Table 3, you can find the criteria weights calculated with AHP.

It is worth mentioning that the weights of Table 3 are in accordance with real condition of the construction industry in Iran. Weights of $x_{1}$ (Cost) show the importance of direct cost for each party. As the productivity is lower in public sector, the main employer of construction projects in Iran, and for the reason that employer is not responsible for the cost over-run based on contractor's low productivity and also for the fact that cost over-run is a prevalent problem in Iran the expert team defined employer's weight for $x_{1}$ really low comparing with contractor's. But focusing on $x_{2}$, it is a different case. Mostly, employer's loss due to late operation of the project is less than the fine that contractor must pay in the case of delay. This can be a reason explaining parties' $x_{2}$ weights. Based on experts' idea, uncertainty seems to be more important in the employer's conditions because the weight experts defined for employer's $x_{3}$ is more than contractor's. Contractors usually try more to protect the amicable relations between parties. But the difference between two parties is not very high. It is interesting that experts believe that prestigious costs for employers are significantly higher than contractors. Usually, there are less responsible persons in contractor's side that should decide the proper dispute resolution, so the freedom of the responsible person solving the dispute is more important for employer. Also, it can be concluded that based on experts' responses $x_{1}$ has the lowest weight for the employer. It could be for the reason that government is the routine owner of the projects, so as a less efficient sector the final project cost is less important in comparison with other factors like government's public image. It is worth mentioning that we allocate a grey weight for each criterion. Different conditions may affect the criteria weights. So, researchers can use the appropriate criteria weight estimation method among the possible options to revise these weights for future cases. We recommend the weights with a range. Also, the sum of each limit should be equal to one.

\subsection{Calculating criteria's value for alternatives}

In the next step, the cost relating to any of the alternatives was calculated. Here, we only consider direct cost. In Table 4.A and 4.B, you can find the elements consisting the costs of both parties in different alternatives. The delay duration for $A_{1}, A_{2}$ and $A_{3}$ are 4.8, 0 and 3.6, respectively. The delay duration in the case project terminates would be 8 months. This duration includes terminating the current contract and choosing another contractor. Then both parties were asked to score their own values for $x_{3}$ to $x_{8}$, with a value among 1 (very low), 2 (low), 3 (medium), 4 (high) and 5 (very high). Criteria values of the alternatives can be found in Table 5. In Khanzadi et al. (2016), further delineation about the calculation of parties' direct cost is presented.

Table 4.A. Elements consisting employer's costs for different alternatives (in million\$)

\begin{tabular}{c|c|c|c|c}
\hline & $\begin{array}{c}\text { Delay } \\
\text { fine }\end{array}$ & $\begin{array}{c}\text { Loss due to deprivation } \\
\text { from project's timely } \\
\text { utilization }\end{array}$ & $\begin{array}{c}\text { Cost of } \\
\text { holding } \\
\text { another } \\
\text { tender }\end{array}$ & $\begin{array}{c}\text { Employer's } \\
\text { total direct } \\
\text { cost }\end{array}$ \\
\hline$A_{1}$ & +4 & -10 & - & -6 \\
$A_{2}$ & - & - & - & 0 \\
$A_{3}$ & - & -7.2 & - & -7.2 \\
$A_{4}$ & - & -10 & -4 & -14 \\
\hline
\end{tabular}

\section{Proposing the solution}

Each of the contractor and employer, decision-makers in the proposed problem, has their own criteria weights and values. Also, some incompletion of information exists here, such as uncertainty about the future. We believe

Table 3. Criteria weights

\begin{tabular}{lcccccccc}
\hline & $x_{1}$ & $x_{2}$ & $x_{3}$ & $x_{4}$ & $x_{5}$ & $x_{6}$ & $x_{7}$ & $x_{8}$ \\
\hline For contractor & 0.385 & 0.229 & 0.039 & 0.061 & 0.051 & 0.061 & 0.082 & 0.091 \\
For employer & 0.035 & 0.352 & 0.053 & 0.044 & 0.125 & 0.094 & 0.172 & 0.125 \\
\hline
\end{tabular}


Table 4.B. Elements consisting contractor's costs for different alternatives (in million \$)

\begin{tabular}{c|c|c|c|c|c}
\hline & Delay fine & Crash cost & $\begin{array}{c}\text { Increased cost due to } \\
\text { contractor's poor performance }\end{array}$ & $\begin{array}{c}\text { Loss due to deprivation from } \\
\text { next payments of this project }\end{array}$ & $\begin{array}{c}\text { Contractor's } \\
\text { total direct cost }\end{array}$ \\
\hline$A_{1}$ & -4 & -0.9 & -5.9 & - & -10.8 \\
$A_{2}$ & - & -9.8 & -5.44 & - & -15.24 \\
$A_{3}$ & - & -3.1 & -5.8 & - & -8.9 \\
$A_{4}$ & - & - & -5 & -7 & -12 \\
\hline
\end{tabular}

that all of these values are with some degrees of ambiguity. So, we choose grey game theory to solve this MCDM problem.

As it can be seen, the problem is taken as a discrete zero-sum two-person matrix game with grey numbers. The players are contractor and employer of the delayed project and all of the values are the grey numbers with preferences of both parties as the limits. Below is presented description of the game.

\subsection{Case study analysis}

The first stage is grey decision-making matrix (GDMM) forming. In the GMCDM of the discrete optimisation problem any problem to be solved is represented by the following DMM of preferences for $m$ reasonable alternatives (rows) rated on $n$ attributes (columns):

$$
\begin{gathered}
\tilde{X}=\left[\begin{array}{ccccc}
\otimes x_{01} & \cdots & \otimes x_{0 j} & \cdots & \otimes x_{0 n} \\
\vdots & \ddots & \vdots & \ddots & \vdots \\
\otimes x_{i 1} & \cdots & \otimes x_{i j} & \cdots & \otimes x_{i n} \\
\vdots & \ddots & \vdots & \ddots & \vdots \\
\otimes x_{m 1} & \cdots & \otimes x_{m j} & \cdots & \otimes x_{m n}
\end{array}\right] ; \\
i=\overline{0, m} ; j=\overline{1, n},
\end{gathered}
$$

where: $m$ - number of alternatives; $n$ - number of attributes describing each alternative; $\otimes x_{i j}=\left(\otimes x_{i j \alpha}, \otimes x_{i j \beta}\right)=$ - grey value representing the performance value of the $i$ alternative in terms of the $j$ attribute.

Usually, the performance values $\otimes x_{i j}$ and the attributes weights $\otimes w_{j}$ (denotes the relative significance of the attribute) are viewed as the entries of a DMM. Table 5 provides the basic data needed for the resolution. The values in the first row are the criteria weights proposed by the expert team.
As the criteria values have different dimensions, they must be dimensionless to be used in matrix game theory. So different transformation formulas have been tested (Zavadskas et al. 2003).

In the second stage the initial values of all the attributes are normalized - defining values $\otimes \bar{x}_{i j}$ of normalised decision-making matrix $\otimes \bar{X}$ :

$$
\begin{gathered}
\otimes \bar{X}=\left[\begin{array}{ccccc}
\otimes \bar{x}_{01} & \cdots & \otimes \bar{x}_{0 j} & \cdots & \otimes \bar{x}_{0 n} \\
\vdots & \ddots & \vdots & \ddots & \vdots \\
\otimes \bar{x}_{i 1} & \cdots & \otimes \bar{x}_{i j} & \cdots & \otimes \bar{x}_{i n} \\
\vdots & \ddots & \vdots & \ddots & \vdots \\
\otimes \bar{x}_{m 1} & \cdots & \otimes \bar{x}_{m j} & \cdots & \otimes \bar{x}_{m n}
\end{array}\right] ; \\
i=\overline{0, m} ; j=\overline{1, n} .
\end{gathered}
$$

The linear transformation results in more rational values. They are normalised with Eqns (9)-(10), when optimum is maximum or minimum, respectively.

$$
\begin{gathered}
\otimes \bar{x}_{i j}=\frac{\tilde{x}_{i j}-\min _{i} \tilde{x}_{i j}}{\max _{i} \tilde{x}_{i j}-\min _{i} \tilde{x}_{i j}} \quad \bar{x}_{i j \alpha}=\frac{\tilde{x}_{i j \alpha}-\min _{i} \tilde{x}_{i j}}{\max _{i} \tilde{x}_{i j}-\min _{i} \tilde{x}_{i j}} ; \\
\bar{x}_{i j \beta}=\frac{\tilde{x}_{i j \beta}-\min _{i} \tilde{x}_{i j}}{\max _{i} \tilde{x}_{i j}-\min _{i} \tilde{x}_{i j}} ; \\
\oplus \bar{x}_{i j}=\frac{\max _{i} \tilde{x}_{i j}-\tilde{x}_{i j}}{\max _{i} \tilde{x}_{i j}-\min _{i} \tilde{x}_{i j} ; \quad \bar{x}_{i j \alpha}=\frac{\max _{i} \tilde{x}_{i j \alpha}-\tilde{x}_{i j}}{\max _{i} \tilde{x}_{i j}-\min _{i} \tilde{x}_{i j}} ;} \\
\bar{x}_{i j \beta}=\frac{\max _{i} \tilde{x}_{i j \beta}-\tilde{x}_{i j}}{\max _{i} \tilde{x}_{i j}-\min _{i} \tilde{x}_{i j}} .
\end{gathered}
$$

\begin{tabular}{|c|c|c|c|c|c|c|c|c|c|c|c|c|c|c|c|c|}
\hline & \multicolumn{2}{|c|}{$\otimes x_{1}$} & \multicolumn{2}{|c|}{$\otimes x_{2}$} & \multicolumn{2}{|c|}{$\otimes x_{3}$} & \multicolumn{2}{|c|}{$\otimes x_{4}$} & \multicolumn{2}{|c|}{$\otimes x_{5}$} & \multicolumn{2}{|c|}{$\otimes x_{6}$} & \multicolumn{2}{|c|}{$\otimes x_{7}$} & \multicolumn{2}{|c|}{$\otimes x_{8}$} \\
\hline & A & $\beta$ & $\alpha$ & $\beta$ & $\alpha$ & $\beta$ & $\alpha$ & $\beta$ & $\alpha$ & $\beta$ & $\alpha$ & B & $\alpha$ & $\beta$ & A & $\beta$ \\
\hline$w$ & $\stackrel{0}{0}$ & $\begin{array}{l}\infty \\
\infty \\
\\
0\end{array}$ & तె & $\begin{array}{l}\tilde{n} \\
\text { ?ै? } \\
\text { ô }\end{array}$ & ڤે. & $\stackrel{\tilde{o}}{\tilde{0}}$ & 竎 & $\vec{\circ}$ & $\vec{s}$ & $\stackrel{2}{\mathfrak{1}}$ & $\vec{\circ}$ & ơ & $\begin{array}{l}\text { Oे } \\
\stackrel{0}{0}\end{array}$ & $\stackrel{\frac{1}{5}}{0}$ & $\overline{8}$ & $\stackrel{2}{3}$ \\
\hline$A_{1}$ & 10.8 & 6 & 4.8 & 4.8 & 2 & 2 & 3 & 5 & 2 & 2 & 2 & 3 & 2 & 4 & 4 & 5 \\
\hline$A_{2}$ & 15.25 & 0 & 0 & 0 & 2 & 1 & 2 & 5 & 1 & 1 & 3 & 5 & 2 & 5 & 5 & 5 \\
\hline$A_{3}$ & 8.9 & 7.2 & 3.6 & 3.6 & 3 & 3 & 3 & 3 & 2 & 2 & 4 & 4 & 3 & 3 & 3 & 3 \\
\hline$A_{4}$ & 14 & 12 & 8 & 8 & 4 & 4 & 3 & 3 & 2 & 3 & 3 & 3 & 2 & 5 & 2 & 4 \\
\hline
\end{tabular}

Table 5. Weight factors, criteria and alternatives of the proposed zero-sum two-person matrix game of the delayed project 
Table 6 . The normalized alternative-criteria matrix

\begin{tabular}{|c|c|c|c|c|c|c|c|c|c|c|c|c|c|c|c|c|}
\hline & \multicolumn{2}{|c|}{$\otimes \bar{x}_{1}$} & \multicolumn{2}{|c|}{$\otimes \bar{x}_{2}$} & \multicolumn{2}{|c|}{$\otimes \bar{x}_{3}$} & \multicolumn{2}{|c|}{$\otimes \bar{x}_{4}$} & \multicolumn{2}{|c|}{$\otimes \bar{x}_{5}$} & \multicolumn{2}{|c|}{$\otimes \bar{x}_{6}$} & \multicolumn{2}{|c|}{$\otimes \bar{x}_{7}$} & \multicolumn{2}{|c|}{$\otimes \bar{x}_{8}$} \\
\hline & $\alpha$ & $\beta$ & $\alpha$ & $\beta$ & $\alpha$ & $\beta$ & $\alpha$ & $\beta$ & $\alpha$ & $\beta$ & $\alpha$ & $\beta$ & $\alpha$ & $\beta$ & $\alpha$ & $\beta$ \\
\hline$w$ & 0.03 & 385 & 0.229 & 0.352 & 0.039 & 0.053 & .044 & .061 & 0.051 & 0.125 & 0.061 & 0.094 & 0.082 & 0.172 & 0.091 & 0.125 \\
\hline$A_{1}$ & 0.29 & 0.607 & 0.400 & 0.400 & 0.667 & 0.667 & 0.333 & 1.000 & 0.500 & 0.500 & 0.000 & 0.333 & 0.000 & 0.667 & 0.667 & 1.000 \\
\hline$A_{2}$ & 0.000 & 1.000 & 1.000 & 1.000 & 0.667 & 1.000 & 0.000 & 1.000 & 1.000 & 1.000 & 0.333 & 1.000 & 0.000 & 1.000 & 1.000 & 1.000 \\
\hline$A_{3}$ & 0.416 & 0.528 & 0.550 & 0.550 & 0.333 & 0.333 & 0.333 & 0.333 & 0.500 & 0.500 & 0.667 & 0.667 & 0.333 & 0.333 & 0.333 & 0.333 \\
\hline$A_{4}$ & 0.082 & 0.213 & 0.000 & 0.000 & 0.000 & 0.000 & 0.333 & 0.333 & 0.500 & 0.000 & 0.333 & 0.333 & 0.000 & 1.000 & 0.000 & 0.667 \\
\hline
\end{tabular}

In Table 6, the normalized decision-making matrix is shown.

\subsection{Rules for games with grey numbers}

Laplace's solution is proposed when all probabilities of the other player are equal (Bernoulli 1738). His solution is $S_{1}^{*}$ in Eqn (11):

$$
\begin{array}{r}
S_{1}^{*}=\left\{S_{1 i} \mid S_{1 i} \in S_{1} \cap \max _{i}\left(1 / n \sum_{j=1}^{n} \otimes \bar{x}_{i j}=\right.\right. \\
\left.\left.\left(\frac{1}{2 n}\right) \sum_{j=1}^{n}\left(\bar{x}_{i j \alpha}+\bar{x}_{i j \beta}\right), i=\overline{0, m}\right)\right\} .
\end{array}
$$

Hurwicz believed that the optimal strategy lies between the best and the worst result. He proposed Eqn (12) (Hurwicz 1951). The $\lambda$ value defines the different optimism degrees of the solution. When $\lambda=1$, the solution would be the most pessimistic (Werner's rule). Also, $\lambda=$ 0 can result in the solution with the highest risk:

$$
\begin{aligned}
S_{2}^{*}= & \left\{S_{2 i} \mid S_{2 i} \in S_{2} \cap \max _{i} h_{i} \cap h_{i}=\min _{i} \otimes \bar{x}_{i j}+\right. \\
& (1-\lambda) \max _{j} \otimes \bar{x}_{i j}=\min _{i} \bar{x}_{i j \alpha}+ \\
& \left.(1-\lambda) \max _{j} \bar{x}_{i j \beta}=\cap 0 \leq \lambda \leq 1\right\} .
\end{aligned}
$$

It is possible to evaluate the attributes with weights $0<\otimes w_{j}<1$. But if applying the different weights of the criteria, Bayes (Arrow 1949) and Hodges and Lehmann (1952) proposed different rules.

For this reason, is defining normalized-weighted matrix - only well-founded weights should be used because weights are always subjective and influence the solution. The values of weight $\otimes w_{j}$ are usually determined by the expert evaluation method. The sum of weights $w_{j}$ would be limited as follows:

$$
\frac{1}{2} \sum_{j=1}^{n}\left(w_{i j \alpha}+w_{i j \beta}\right)=1
$$

$$
\begin{gathered}
\otimes \hat{X}=\left[\begin{array}{ccccc}
\otimes \hat{x}_{01} & \cdots & \otimes \hat{x}_{0 j} & \cdots & \otimes \hat{x}_{0 n} \\
\vdots & \ddots & \vdots & \ddots & \vdots \\
\otimes \hat{x}_{i 1} & \cdots & \otimes \hat{x}_{i j} & \cdots & \otimes \hat{x}_{i n} \\
\vdots & \ddots & \vdots & \ddots & \vdots \\
\otimes \hat{x}_{m 1} & \cdots & \otimes \hat{x}_{m j} & \cdots & \otimes \hat{x}_{m n}
\end{array}\right] ; \\
i=\overline{0, m} ; j=\overline{1, n} .
\end{gathered}
$$

Normalised-weighted values of all the attributes calculated as follows:

$$
\begin{gathered}
\oplus \hat{x}_{i j}=\otimes \bar{x}_{i j} \otimes w_{j} ; \hat{x}_{i j \alpha}=\bar{x}_{i j \alpha} w_{j \alpha} ; \\
\hat{x}_{i j \beta}=\bar{x}_{i j \beta} w_{j \beta} ; i=\overline{1, m} ; j=\overline{1, n},
\end{gathered}
$$

where $w_{j}$ is the weight (importance) of the $j$ attribute and $\otimes \bar{x}_{i j}$ is the normalized rating of the $j$ attribute.

In Eqn (16) as Bayes's rule, $S_{3}^{*}$ determines the maximum expected value when the probabilities for opponent's strategies are given:

$$
\begin{aligned}
S_{3}^{*}= & \left\{S_{3 i} \mid S_{3 i} \in S_{3} \cap \max _{i}\left(\sum_{j=1}^{n} \otimes \hat{x}_{i j}\right)=\right. \\
& \left.\max _{i}\left(\frac{1}{2} \sum_{j=1}^{n}\left(\otimes \hat{x}_{i j \alpha}+\otimes \hat{x}_{i j \beta}\right)\right)=\cap \frac{1}{2} \sum_{j=1}^{n} \otimes w_{j}=1\right\} .
\end{aligned}
$$

In Hodges-Lehmann's rule (Eqn (17)), $\lambda$ expresses the confidence degree of the solution. $\Lambda=0$ means no confidence (Wald's rule), while $\lambda=1$ shows the highest confidence (equals Bayes's rule):

$$
\begin{gathered}
\mathrm{S}_{4}^{*}=\left\{\mathrm{S}_{4 \mathrm{i}} \mid \mathrm{S}_{4 \mathrm{i}} \in \mathrm{S}_{4} \cap \max _{i}\left[\lambda \sum_{j=1}^{n} \otimes \hat{x}_{i j}+(1-\lambda) \min _{i} \otimes \hat{x}_{i j}\right]=\right. \\
\max _{i}\left[\lambda \frac{1}{2} \sum_{j=1}^{n}\left(\otimes \hat{x}_{i j \alpha}+\otimes \hat{x}_{i j \beta}\right)+(1-\lambda) \min _{i} \otimes \hat{x}_{i j \alpha}\right]= \\
\cap 0 \leq \lambda \leq 1\} .
\end{gathered}
$$


Table 7. Results of the Laplace's and Hurwicz's rules

\begin{tabular}{c|c|c|c|c|c|c}
\hline \multirow{2}{*}{} & \multirow{2}{*}{ Laplace's rule } & \multicolumn{5}{|c}{ Hurwicz's rule (ranks) } \\
\cline { 3 - 7 } & & $\lambda=0$ & $\lambda=0.25$ & $\lambda=0.50$ & $\lambda=0.75$ & $\lambda=1$ (Werner's) \\
\hline$A_{1}$ & $0.502(2)$ & $0.167(3)$ & $0.333(2)$ & $0.500(2)$ & $0.667(2)$ & $0.833(2)$ \\
$A_{2}$ & $0.750(1)$ & $0.500(1)$ & $0.625(1)$ & $0.750(1)$ & $0.875(1)$ & $1.000(1)$ \\
$A_{3}$ & $0.440(3)$ & $0.333(2)$ & $0.417(2)$ & $0.500(2)$ & $0.583(3)$ & $0.667(3)$ \\
$A_{4}$ & $0.237(4)$ & $0.000(4)$ & $0.125(4)$ & $0.250(4)$ & $0.375(4)$ & $0.500(4)$ \\
\hline
\end{tabular}

Note: Variants' ratings are indicated in brackets.

Table 8. Results of the Bayes's and Hodges-Lehman's rules

\begin{tabular}{c|c|c|c|c|c|c}
\hline \multirow{2}{*}{} & \multirow{2}{*}{ Bayes's rule } & \multicolumn{5}{|c}{ Hodges-Lehman's rule (ranks) } \\
\cline { 3 - 7 } & & $\lambda=0$ (Wald's) & $\lambda=0.25$ & $\lambda=0.50$ & $\lambda=0.75$ & $\lambda=1$ (Bayes's) \\
\hline$A_{1}$ & $0.415(3)$ & $0.010(3)$ & $0.111(3)$ & $0.213(3)$ & $0.314(3)$ & $0.415(3)$ \\
$A_{2}$ & $0.651(1)$ & $0.017(1)$ & $0.176(1)$ & $0.334(1)$ & $0.493(1)$ & $0.651(1)$ \\
$A_{3}$ & $0.456(2)$ & $0.015(2)$ & $0.126(2)$ & $0.236(2)$ & $0.346(2)$ & $0.456(2)$ \\
$A_{4}$ & $0.166(4)$ & $0.000(4)$ & $0.041(4)$ & $0.083(4)$ & $0.124(4)$ & $0.166(4)$ \\
\hline
\end{tabular}

Note: Variants' ratings are indicated in brackets.

\subsection{Calculation results}

Calculations were made applying Eqns (11)-(17). Tables 7 and 8 show the results of Laplace's, Hurwicz's, Bayes's and Hodges-Lehman's rules. It should be mentioned that in these rules criteria weights are assumed equal in Table 7, and criteria weights have been applied in Table 8. Also based on different $\lambda$ values in Hurwicz's and Hodges-Lehman's rule, different solutions are proposed for several risk levels.

According to the calculations related to the proposed case study, it can be inferred that $A_{2}$ (Compensation of the total delay by the contractor) was the suggested alternative regardless of the applied rule. It was the suggested alternative while incurs the highest cost to the contractor, among all of the alternatives. The reason is that based on the logic of the applied rules, any input value was a range with limits of contractor and employers' priorities. But then, $A_{4}$ (Contract termination) was always in the last rank. Focusing on the different states of Table 8, the alternative ranking is as $A_{2}, A_{3}, A_{1}$ and $A_{4}$, respectively. It should be noted that weight factors are applied in the rules of Bayes and Hodges-Lehmann. But using rules of Laplace and Hurwicz, without the weight factors, the place of $A_{1}$ and $A_{3}$ are changed (Table 7). This difference in ranking relates to application of different risk levels. The present research consolidates the fact that both parties usually try to continue the project, as much as possible. Also, they do not consider the termination of the contract as an optimal solution for its high side costs.

\section{Discussion}

In the present research, players have opposing interests about each criterion. So, weights and values of the cri- teria are different for them. Solving these types of problems with crisp numbers, push the decision makers away from reality. So, grey numbers are suggested to prepare the chance for using the values in the shape of a range. With reference to calculation results, an attractive ability of grey numbers has been used for the integration of decision makers' ideas in a dispute. In the proposed game and using the expert judgement, indirect payoffs of the players resulted from the factors as information uncertainty, prestigious cost, etc. were applied in decision making. So, players' total payoff formed the higher and lower limits of criteria values. Also, importance degree for each criterion has been applied with a grey number to handle the vagueness. The selected alternative for the studied case was related to the projects' conditions. Contract type, project location and other factors may change the available alternatives, and also how much each of the criteria affects the final solution. For this purpose and also a generalization of the results, further researches in future would be necessary to understand the trade-offs between the participants of the projects. Although, AHP is an easy to use and useful tool for uniting experts' ideas, but exerting experts' opinions in the fuzzy form may lead to more reliable results. So, comparison between AHP and fuzzy-AHP may be useful. Of course, fuzzy calculations should be computerised for enhancing its usability for manager decision makers. Result generalisation and exact applicable suggestions would be sensible when the above-mentioned points are taken into consideration. Dispute problems are repetitive in nature. Although we proposed a dispute resolution method to the parties, they are not protected against the dispute renewal. In that case, parties can reuse the proposed resolution method or based on future researches some dynamic methods should be found for repetitive dispute resolution proposals. This could be achieved with some tools like System Dynamics. 


\section{Conclusions}

A dispute is a common issue in construction industry that participants of a project should resolve it operatively. Dispute problem is usually multi-dimensional MCDM with discrete alternatives of the solution. Information for such problems is vague, and cannot be described by crisp criteria values. Also, the problem has two sides as decisionmakers with different vague weight for each side and different vague values for criteria. So, grey numbers are very suitable for such problems having uncertainty .Due to ambiguity in the problem, grey values have been applied. A new hybrid MCDM model of discrete zero-sum two-person matrix games with grey numbers is developed as a framework to solve dispute problems. Based on expert judgments, grey value criteria weights are determined by AHP; and alternatives are ranked.Case study results show that proposed model determines the optimal solution based on different risk values. This allows the decision makers to choose their best, according to their risk attitude. This model integrates some linguistic criteria together with time and cost, also with grey criteria values for them. As a result, direct and indirect payoffs for parties are calculated more realistic.

A real case study of dispute resolution determination illustrates the proposed dispute resolution framework. Four possible discrete alternatives and eight criteria (cost, delay duration, and some linguistic criteria) have been defined. Then, decision makers calculated the criteria values with grey values and the alternatives have been prioritised in different situations, using the grey number rules. Results indicate that two parties prefer to compensate the total delay. Also, termination is the last alternative that decision makers choose. It means that they prefer to reach an agreement as soon as possible to avoid lengthy bargaining or litigation.

In conclusion, the proposed model is easy to apply and develop for similar conditions.

\section{References}

Ahmed, M. O.; El-adaway, I. H.; Coatney, K. T.; Eid, M. S. 2016. Construction bidding and the winner's curse: Game theory approach, Journal of Construction Engineering and Management 142(2), 04015076. https://doi.org/10.1061/(ASCE)CO.1943-7862.0001058

Antuchevičiene, J.; Turskis, Z.; Zavadskas, E. K. 2006. Modelling renewal of construction objects applying methods of the game theory, Technological and Economic Development of Economy 12(4): 263-268.

Arrow, K. J. 1949. Bayes and Minimax solutions of sequential decision problems, Econometrica 17(3-4): 213-243. https://doi.org/10.2307/1905525

Asgari, S.; Afshar, A.; Madani, K. 2014. Cooperative Game theoretic framework for joint resource management in construction, Journal of Construction Engineering and Management 140(3), 4013066. https://doi.org/10.1061/(ASCE)CO.1943-7862.0000818

Assaf, S. A.; Al-Hejji, S. 2006. Causes of delay in large construction projects, International Journal of Project Management 24(4): 349-357.

https://doi.org/10.1016/j.ijproman.2005.11.010
Bernoulli, D. 1738. Specimen theoriae novas de mesure sortis, Comentarii Academiae Scientarium Inperialis Petropolitanae, 175-192.

Castro, J.; Gómez, D.; Tejada, J. 2007. A project game for PERT networks, Operations Research Letters 35(6): 791-798. https://doi.org/10.1016/j.orl.2007.01.003

Chan, D. W. M.; Kumaraswamy, M. M. 2002. Compressing construction durations : lessons learned from Hong Kong building projects, International Journal of Project Management 20(1): 23-35.

https://doi.org/10.1016/S0263-7863(00)00032-6

Chan, E. H. W.; Suen, H. C. H. 2005. Dispute resolution management for international construction projects in China, Management Decision 13(4): 589-602. https://doi.org/10.1108/00251740510593576

Chan, E. H.; Suen, H. C. H.; Chan, C. K. L. 2006. MAUT-based Dispute resolution selection model prototype for international construction projects, Journal of Construction Engineering and Management 132(5): 444-451.

https://doi.org/10.1061/(ASCE)0733-9364(2006)132:5(444)

Chen, T. C.; Lin, Y. C.; Wang, L. C. 2012. The analysis of BOT strategies based on game theory - case study on Taiwan's high speed railway project, Journal of Civil Engineering and Management 18(5): 662-674. https://doi.org/10.3846 $/ 13923730.2012 .723329$

Chen, Y.; Zhang, Y.; Zhang, S. 2014. Impacts of different types of owner-contractor conflict on cost performance in construction projects, Journal of Construction Engineering and Management 140(6), 04014017. https://doi.org/10.1061/(ASCE)CO.1943-7862.0000852

Cheung, S.-O.; Suen, H. C. H. 2002. A multi-attribute utility model for dispute resolution strategy selection, Construction Management and Economics 20(7): 557-568. https://doi.org/10.1080/01446190210157568

Cheung, S.-O.; Yiu, T. W.; Chan, H. W. 2010. Exploring the potential for predicting project dispute resolution satisfaction using logistic regression, Journal of Construction Engineering and Management 136(5): 508-517. https://doi.org/10.1061/(ASCE)CO.1943-7862.0000157

Chong, H.; Zin, M. R. 2012. Selection of dispute resolution methods: factor analysis approach, Engineering, Construction and Architectural Management 19(4): 428-443. https://doi.org/10.1108/09699981211237120

Chou, J.-S. 2012. Comparison of multilabel classification models to forecast project dispute resolutions, Expert Systems with Applications 39(11): 10202-10211. https://doi.org/10.1016/j.eswa.2012.02.103

De Clerck, D.; Demeulemeester, E. 2016. Creating a more competitive PPP procurement market: Game theoretical analysis, Journal of Management in Engineering 32(6), 04016015. https://doi.org/10.1061/(ASCE)ME.1943-5479.0000440

Deng, J. L. 1982. Control problems of grey system, Systems and Control Letters 1(5): 288-294. https://doi.org/10.1016/S0167-6911(82)80025-X

Deng, J. L. 1989. Introduction to grey system theory, The Journal of Grey Theory 1(1): 1-24

Eid, M. S.; El-adaway, I. H.; Coatney, K. T. 2015. Evolutionary stable strategy for postdisaster insurance: game theory approach, Journal of Management in Engineering 31(6), 04015005. https://doi.org/10.1061/(ASCE)ME.19435479.0000357

El-adaway, I. H.; Kandil, A. A. 2010. Multiagent system for construction dispute resolution (MAS-COR), Journal of Construction Engineering and Management 136(3): 303-315. https://doi.org/10.1061/(ASCE)CO.1943-7862.0000144

Estévez-Fernández, A. 2012. A game theoretical approach to sharing penalties and rewards in projects, European Journal of Operational Research 216(3): 647-657. https://doi.org/10.1016/j.ejor.2011.08.015 
Fang, Z.; Liu, S.; Shi, H.; Lin, Y. 2010. Grey game theory and its applications in economic decision-making. Auerbach Publications, Taylor \& Francis Group.

Gardiner, P. 2005. Project management. A strategic planning approach. Palgrave.

Gebken, R. J.; Gibson, G. E. 2006. Quantification of costs for dispute resolution procedures in the construction industry, Journal of Professional Issues in Engineering Education and Practice 132(3): 264-271. https://doi.org/10.1061/ (ASCE)1052-3928(2006)132:3(264)

González, P.; González, V.; Molenaar, K.; Orozco, F. 2014. Analysis of causes of delay and time performance in construction projects, Journal of Construction Engineering and Management 140(1), 04013027. https://doi.org/10.1061/(ASCE)CO.1943-7862.0000721

Harmon, K. M. J. 2003. Conflicts between owner and contractors: Proposed intervention process, Journal of Management in Engineering 19(3): 121-125. https://doi. org/10.1061/(ASCE)0742-597X(2003)19:3(121)

He, W.; Tang, W.; Wei, Y.; Duffield, C. F.; Lei, Z. 2016. Evaluation of cooperation during project delivery: Empirical study on the hydropower industry in Southwest China, Journal of Construction Engineering and Management 142(2), 04015068. https://doi.org/10.1061/(ASCE) CO.1943-7862.0001044

Hipel, K. W.; Kilgour, D. M.; Fang, L. 2011. The graph model for conflict resolution, in Wiley encyclopedia of operations research and management science. Wiley. https://doi.org/10.1002/9780470400531.eorms0882

Ho, S. P. 2005. Bid compensation decision model for projects with costly bid preparation, Journal of Construction Engineering and Management 131(2): 151-159. https://doi.org/10.1061/(ASCE)0733-9364(2005)131:2(151)

Ho, S. P. 2006. Model for financial renegotiation in public-private partnership projects and its policy implications: game theoretic view, Journal of Construction Engineering and Management 132(7): 678-688. https://doi.org/10.1061/ (ASCE)0733-9364(2006)132:7(678)

Ho, S. P.; Hsu, Y. 2014. Bid compensation theory and strategies for projects with heterogeneous bidders: a Game theoretic analysis, Journal of Management in Engineering 30(5), 04014022. https://doi.org/10.1061/(ASCE)ME.19435479.0000212

Ho, S. P.; Liu, L. Y. 2004. Analytical model for analyzing construction claims and opportunistic bidding, Journal of Construction Engineering and Management 130(1): 94-104. https://doi.org/10.1061/(ASCE)07339364(2004)130:1(94)

Hodges, J. L.; Lehmann, E. L. 1952. The use of previous experience in reaching statistical decision, Annals of Mathematics Studies 23(3): 396-407. https://doi.org/10.1214/aoms/1177729384

Hsueh, S. L.; Yan, M. R. 2011. Contribution-based profit-sharing scheme for joint ventures, Technological and Economic Development of Economy 17(3): 445-458. https://doi.org/10.3846/20294913.2011.580578

Hurwicz, L. 1951. Optimality criteria for decision making under ignorance. Cowels Commission Discussion Paper: Statistics No. 370.

Jaffar, N.; Abdul Tharim A. H.; Shuib, M. N. 2011. Factors of conflict in construction industry: a literature review, Procedia Engineering 20: 193-202. https://doi.org/10.1016/j.proeng.2011.11.156

Javed, A. A.; Lam, P. T. I.; Chan, A. P. C. 2014. Change negotiation in public-private partnership projects through output specifications: an experimental approach based on game theory, Construction Management and Economics 32(4): 323-348. https://doi.org/10.1080/01446193.2014.895846
Kadry, M.; Osman, H.; Georgy, M. 2016. Causes of construction delays in countries with high geopolitical risks, Journal of Construction Engineering and Management 143(2). https://doi.org/10.1061/(ASCE)CO.1943-7862.0001222

Kassab, M.; Hipel, K.; Hegazy, T. 2006. Conflict resolution in construction disputes using the graph model, Journal of Construction Engineering and Management 132(10): 1043-1052. https://doi.org/10.1061/(ASCE)07339364(2006)132:10(1043)

Kassab, M.; Hegazy, T.; Hipel, K. 2010. Computerized DSS for construction conflict resolution under uncertainty, Journal of Construction Engineering and Management 136(12): 1249-1257. https://doi.org/10.1061/(ASCE)CO.1943-7862.0000239

Kassab, M.; Hipel, K.; Hegazy, T. 2011. Multi-criteria decision analysis for infrastructure privitisation using conflict resolution, Structure and Infrastructure Engineering: Maintenance, Management, Life-Cycle Design and Performance 7(9): 661-671. https://doi.org/10.1080/15732470802677649

Kaufmann, A.; Gupta, M. M. 1985. Introduction to fuzzy arithmetic: Theory and applications. New York: Van Nostrand Reinhold.

Keršuliene, V.; Zavadskas, E. K.; Turskis, Z. 2010. Selection of rational dispute resolution method by applying new stepwise weight assessment ratio analysis (SWARA), Journal of Business Economics and Management 11(2): 243-258. https://doi.org/10.3846/jbem.2010.12

Khanzadi, M.; Eshtehardian, E.; Chalekaee, A. 2016. A game theory approach for optimum strategy of the owner and contractor in delayed projects, Journal of Civil Engineering and Management 22(8): 1066-1077. https://doi.org/10.3846/13923730.2016.1210222

Lee, C. K.; Yiu, T. W.; Cheung, S. O. 2016. Selection and use of Alternative Dispute Resolution (ADR) in construction projects - Past and future research, International Journal of Project Management 34(3): 494-507. https://doi.org/10.1016/j.ijproman.2015.12.008

Lee, S. 2015. Determination of priority weights under multiattribute decision-making situations: AHP versus Fuzzy AHP, Journal of Construction Engineering \& Management 141(2).

https://doi.org/10.1061/(ASCE)CO.1943-7862.0000897

Li, Y.; Wang, X.; Wang, Y. 2017. Using bargaining game theory for risk allocation of public-private partnership projects: Insights from different alternating offer sequences of participants, Journal of Construction Engineering and Management $143(3)$. https://doi.org/10.1061/(ASCE)CO.1943-7862.0001249

Lin, Y.; Chen, M. Y.; Liu, S. 2004. Theory of grey systems: capturing uncertainties of grey information, Kybernetes 33(2): 196-218. https://doi.org/10.1108/03684920410514139

Lv, J.; Ye, G.; Liu, W.; Shen, L.; Wang, H. 2015. Alternative model for determining the optimal concession period in managing BOT transportation projects, Journal of Management in Engineering 31(4), 04014066. https://doi.org/10.1061/(ASCE)ME.1943-5479.0000291

Management and Programing Organization of Iran. 1999. Sharayet Omoomi Peyman.

Medineckiene, M.; Zavadskas, E. K.; Turskis, Z. 2011. Dwelling selection by applying fuzzy game theory, Archives of Civil and Mechanical Engineering 11(3): 681-697. https://doi.org/10.1016/S1644-9665(12)60109-5

Naderpajouh, N.; Mahdavi, A.; Hastak, M.; Aldrich, D. P. 2014. Modeling social opposition to infrastructure development, Journal of Construction Engineering and Management 140(8): 1-10. https://doi.org/10.1061/(ASCE)CO.19437862.0000876 
Ng, H. S.; Peña-mora, F.; Tamaki, T. 2007. Dynamic conflict management in large-scale design and construction projects, Journal of Management in Engineering 23(2): 52-66. https://doi.org/10.1061/(ASCE)0742-597X(2007)23:2(52)

Nguyen, A. T.; Nguyen, L. D.; Le-Hoai, L.; Dang, C. N. 2015. Quantifying the complexity of transportation projects using the fuzzy analytic hierarchy process, International Journal of Project Management 33(6): 1364-1376. https://doi.org/10.1016/j.ijproman.2015.02.007

Peldschus, F.; Zavadskas, E. K. 2012. Gleichgewichtsbetrachtungen fur Bauprozesse-Mehrkriterielle Entscheidungsfindung fur Bauprojekte, Bauingenieur 87: 210-215.

Peldschus, F.; Zavadskas, E. K.; Turskis, Z.; Tamosaitiene, J. 2010. Sustainable assessment of construction site by applying Game theory, Inzinerine Ekonomika-Engineering Economics 21(3): 223-237.

Plebankiewicz, E.; Kubek, D. 2015. Multicriteria selection of the building material supplier using AHP and Fuzzy AHP, Journal of Construction Engineering and Management 142(1). https://doi.org/10.1061/(ASCE)CO.1943-7862.0001033

Polat, G. 2015. Subcontractor selection using the integration of the AHP and PROMETHEE methods, Journal of Civil Engineering and Management 22(8): 1042-1054. https://doi.org/10.3846/13923730.2014.948910

Saaty, T. L. 1980. The analytic hierarchy process. New York, NY: McGraw-Hill.

Shen, L. Y.; Bao, H. J.; Wu, Y. Z.; Lu, W. S. 2007. Using bargaining-game theory for negotiating concession period for BOT-type contract, Journal of Construction Engineering and Management 133(5): 385-392. https://doi.org/10.1061/(ASCE)0733-9364(2007)133:5(385)

Song, X.; Peña-Mora, F.; Menassa, C.; Arboleda, C. 2014. Determining the optimal premium for ADR implementation insurance in construction dispute resolution, Journal of Management in Engineering 30(4), 04014012. https://doi.org/10.1061/(ASCE)ME.1943-5479.0000188

Sunindijo, R.; Hadikusumo, B. 2014. Emotional intelligence for managing conflicts in the sociocultural norms of the Thai construction industry, Journal of Management in Engineering 30(6), 04014025. https://doi.org/10.1061/(ASCE)ME.1943-5479.0000211

Šostak, O. R.; Vakrinienè, S. 2011. Mathematical modelling of dispute proceedings between investors and third parties on allegedly violated third-party rights, Journal of Civil Engineering and Management 17(1): 126-136. https://doi.org/10.3846/13923730.2011.560628

Šostak, O. R.; Makutėnienè, D. 2013a. Modelling a dispute hearing between an investor and the public concerned in administrative courts of the Republic of Lithuania, Technological and Economic Development of Economy 19(3): 489-509. https://doi.org/10.3846/20294913.2013.817489
Šostak, O. R.; Makutėnienė, D. 2013b. Timely determining and preventing conflict situations between investors and third parties: some observations from Lithuania, International Journal of Strategic Property Management 17(4): 390404. https://doi.org/10.3846/1648715X.2013.863239

Tserng, H. P.; Russell, J. S.; Hsu, C.; Lin, C. 2012. Analyzing the role of national PPP units in promoting PPPs : Using new institutional economics and a case study, Journal of Construction Engineering and Management 138(2): 242-249. https://doi.org/10.1061/(ASCE)CO.1943-7862.0000398

Tserng, H. P. H.; Ho, S. S. P.; Chou, J. S. J.; Lin, C. 2014. Proactive measures of governmental debt guarantees to facilitate public-private partnerships project, Journal of Civil Engineering and Management 20(4): 548-560. https://doi.org/10.3846/13923730.2013.801883

Turskis, Z.; Zavadskas E. K. 2010. A novel method for multiple criteria analysis: Grey Additive Ratio Assessment (ARASG) method, Informatica 21(4): 597-610.

Turskis, Z.; Zavadskas, E. K.; Peldschus, F. 2009. Multi-criteria optimization system for decision making in construction design and management, Inzinerine Ekonomika-Engineering Economics 61(1): 7-17.

Unsal, H. I.; Taylor, J. E. 2011. Modeling interfirm dependency : Game theoretic simulation to examine the holdup problem in project networks, Journal of Construction Engineering and Management 137(4): 284-293. https://doi.org/10.1061/(ASCE)CO.1943-7862.0000286

Wang, T.; Wang, S.; Zhang, L.; Huang, Z.; Li, Y. 2016. A major infrastructure risk-assessment framework: Application to a cross-sea route project in China, International Journal of Project Management 34(7): 1403-1415. https://doi.org/10.1016/j.ijproman.2015.12.006

Wu, J.; Kumaraswamy, M. M.; Soo, G. 2011. Regulative measures addressing payment problems in the construction industry: a calculative understanding of their potential outcomes based on gametric models, Journal of Construction Engineering and Management 137(8): 566-573. https://doi.org/10.1061/(ASCE)CO.1943-7862.0000336

Yousefi, S.; Hipel, K. W.; Hegazy, T. 2010. Attitude-based negotiation methodology for the management of construction disputes, Journal of Management in Engineering 26(3): 114-122. https://doi.org/10.1061/(ASCE)ME.19435479.0000013

Yousefi, V.; Yakhchali, S. H.; Khanzadi, M.; Mehrabanfar, E.; Šaparauskas, J. 2016. Proposing a neural network model to predict time and cost claims in construction projects, Journal of Civil Engineering and Management 22(7): 967-978. https://doi.org/10.3846/13923730.2016.1205510

Zavadskas, E. K.; Ustinovichius, L.; Peldschus, F. 2003. Development of software for multiple criteria evaluation, Informatica 14(2): 259-272.

Mostafa KHANZADI. Assistant professor of construction management at Civil Engineering Department of Iran University of Science \& Technology. He had also courses in construction engineering and management at the University of Tehran. His research interests include application of strategic project management, decision support systems, quality management process, and contract management.

Zenonas TURSKIS. Professor at Department of Construction Technology and Management at Vilnius Gediminas Technical University, Lithuania. His research interests include building technology and management, decision-making theory, computer-aided automation in design and expert systems. He is the author of more than 100 research papers, which are referred in WoS database.

Gholamreza GHODRATI AMIRI. Professor of Structural and Earthquake Engineering at Member of Center of Excellence for Fundamental Studies in Structural Engineering, School of Civil Engineering, Iran University of Science \& Technology (IUST). His research interests include seismic hazard assessment and artificial earthquake, seismic assessment and retrofit of structures, and damage detection and health monitoring.

Alireza CHALEKAEE. PhD candidate at the School of Civil Engineering, Iran University of Science and Technology (IUST). He received his MSc degree in the construction management from IUST (2010). His published researches (mostly in Persian) are centered on these areas: 1) Construction management, 2) Dispute resolution methods, and 3) Game theory application. His current research interests include construction management, Game theory application, and interest conflict between owner and contractor. 